
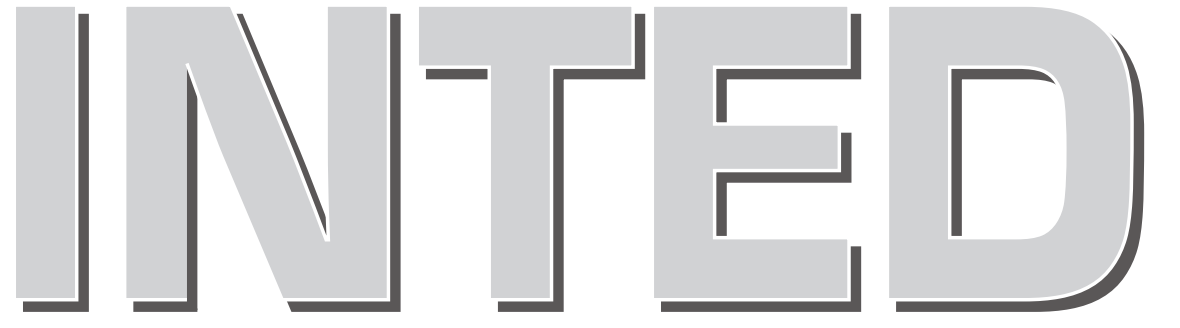

\section{1}

15th International

Technology, Education and

Development Conference

8-9 March, 2021

\section{CONFERENCE PROCEEDINGS}


Published by

IATED Academy

iated.org

INTED2021 Proceedings

15th International Technology, Education and Development Conference

March 8th-9th, 2021

\section{Edited by}

L. Gómez Chova, A. López Martínez, I. Candel Torres

IATED Academy

ISBN: 978-84-09-27666-0

ISSN: $2340-1079$

DL: V-370-2021

Book cover designed by

J.L. Bernat

All rights reserved. Copyright (C) 2021, IATED

The papers published in these proceedings reflect the views only of the authors. The publisher cannot be held responsible for the validity or use of the information therein contained. 


\title{
CONTRIBUTIONS TO THE LEARNING IN LINEAR ALGEBRA: AN EXPERIENCE WITH THE MATHE PLATFORM
}

\author{
P.M. Barros, F. Silva, E. Cordeiro \\ Instituto Politécnico de Bragança (PORTUGAL)
}

\begin{abstract}
The current pandemic context has highlighted the importance of looking for technological alternatives that contribute for students to achieve greater autonomy in their learning. In particular, in the field of mathematics in higher education, it is urgent to find technological instruments that mediate learning, such as interactive content or online platforms.
\end{abstract}

The MathE platform (https://mathe.pixel-online.org), still under development, aims to be a tool to facilitate the acquisition of mathematical skills in the field of higher education. Its main resources are the Self Need Assessment, Final Assessment, Material Didactic and Video Collection and are freely available for students and teachers. It was precisely the resource "Self Need Assessment", that served as the basis for a study with 84 students who attended the course unit of Linear Algebra and Analytical Geometry, as part of the 1st year of a Bachelor in engineering or technology in portuguese higher education. They solved some tasks of self-assessment on Vector Spaces and Linear Transformations, and finally answered a questionnaire in which they expressed their opinion of the platform.

We intend to present the MathE platform and, based on the perceptions/opinions of students and teachers involved in the experiments carried out, analyse its potential for the promoting the teaching of linear algebra.

Keywords: Higher education, MathE platform, self-need assessment, linear algebra.

\section{INTRODUCTION}

The massification of higher education, which results in a large heterogeneity of students, is one of the current training challenges at this level of education ([1]). On the other hand, as Lima, Menezes and Carregã ([2]) consider, the Bologna process entails new assumptions such as initiative, autonomy and self-regulation of the attitude towards students' study and learning. The demands of this paradigm shift include the use of more active, participatory and collaborative teaching and assessment methodologies, contributing to autonomous learning ([3], [4]). This requires more student-centred teaching, with the availability of a variety of resources and educational materials, including information and communication technologies and online platforms to support learning. Currently, the new coronavirus pandemic has highlighted the need to increasingly combine technology with higher education. Through the internet, several educational videos, games and exercises oriented towards learning, interactive content or even digital platforms are already accessible. All this educational technology can be used to mediate learning in the school context or, later, to help consolidate the subjects covered in the classroom.

The scientific area of linear algebra includes topics that require the understanding of several concepts that, almost always, require some degree of abstraction with a view to generalizations, being therefore a domain where students manifest difficulties. According to several studies, higher education students show difficulties both in terms of the propaedeutic knowledge that would be necessary to accompany the course units that focus on this area (e.g. [5], [6], [7], [8], [9]) as inherent in the linear algebra content itself (e.g. [5], [10], [11], [12], [13], [14], [15], [16], [17], [18], [19]).

In this context, it makes perfect sense that higher education teachers who teach linear algebra themes bet on methodological approaches that lead to autonomous work on the part of students and the development of the ability to identify and correct their mistakes, as a way to overcome difficulties. The MathE platform is a digital tool, still under development, that can help achieve this goal. This platform is essentially aimed at teaching mathematics in higher education, although some themes also cover high education content (which may be prerequisites for higher education), and allows students to have access to a free diverse set of resources, such as video collection, teaching material and questions for self-assessment on specific areas of mathematics. 
The study that we present, is based on an experience carried out with 84 students of higher education, who were attending the course unit of Linear Algebra and Analytical Geometry (ALGA) as part of their degree course. These students performed some tasks in the domain of Vector Spaces and Linear Transformations using the potentialities of the "Self Need Assessment" strand of the MathE platform and, subsequently, answered a questionnaire in which, among other aspects, they expressed their opinion on this resource.

It is intended, therefore, to present the MathE platform and, based on the focused investigative scenario, to analyse its potential for the promotion of teaching linear algebra in higher education.

\section{METHODOLOGY}

In the following items, we contextualize the environment in which the study described took place, we briefly characterize the participants and present the research methodology adopted, in relation to the collection of information and data analysis.

\subsection{Study context}

\subsubsection{The MathE platform}

The MathE platform (https://mathe.pixel-online.org) is being developed as part of a project, funded by the European Commission through the Portuguese National Agency for the Erasmus + Program, whose main objective is to facilitate the acquisition of skills in higher education mathematics. Several European institutions are involved in this project, including the Polytechnic Institute of Bragança. The collaboration of a community of teachers made it possible to create and organize a diverse set of educational resources, which are freely available to the educational community, namely:

a) Self Need Assessment - Allows students to take self-assessment tests on selected topics that are already available on the platform.

b) Final Assessment - Allows teachers to prepare final assessments on topics discussed with their students. It will be possible to select questions that are already on the platform or to elaborate other questions that it deems more pertinent. In this space, each teacher can create his own question bank.

c) Video Collection - Set of videos suggested to help resolve the issues presented in the Self Need Assessment.

d) Teaching Materials - Documents to clarify concepts and/or to resolve issues similar to those presented in the self-assessment questionnaires.

At the moment, 15 topics of higher education mathematics are available, some of which are subdivided by subtopics. For example, the topic of Linear Algebra deals with the following subtopics: Matrices and determinants, Systems of linear equations, Vector spaces, Linear transformations and Values and eigenvectors.

Considering the "Self Need Assessment" component, students can select the topic and subtopic to which they intend to carry out a self-assessment. They can also select the degree of difficulty of the questions, choosing the basic or advanced level, according to Fig. 1.

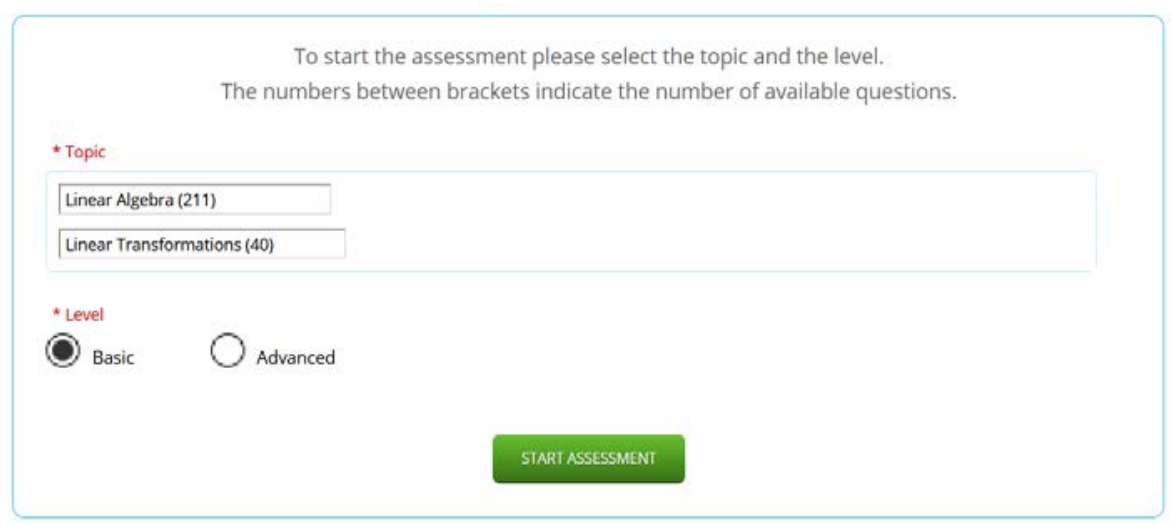

Figure 1. Example for select test topics and question level. 
Both the basic and advanced tests consist of seven multiple-choice questions, with four options with a possible answer to the question and also the alternative "I don't know". At the end of the test, the student has access to all questions with the answers given, being asked to confirm them or to answer any questions still unanswered. After this review, he must submit his responses to receive feedback (Fig. 2) on his correction.

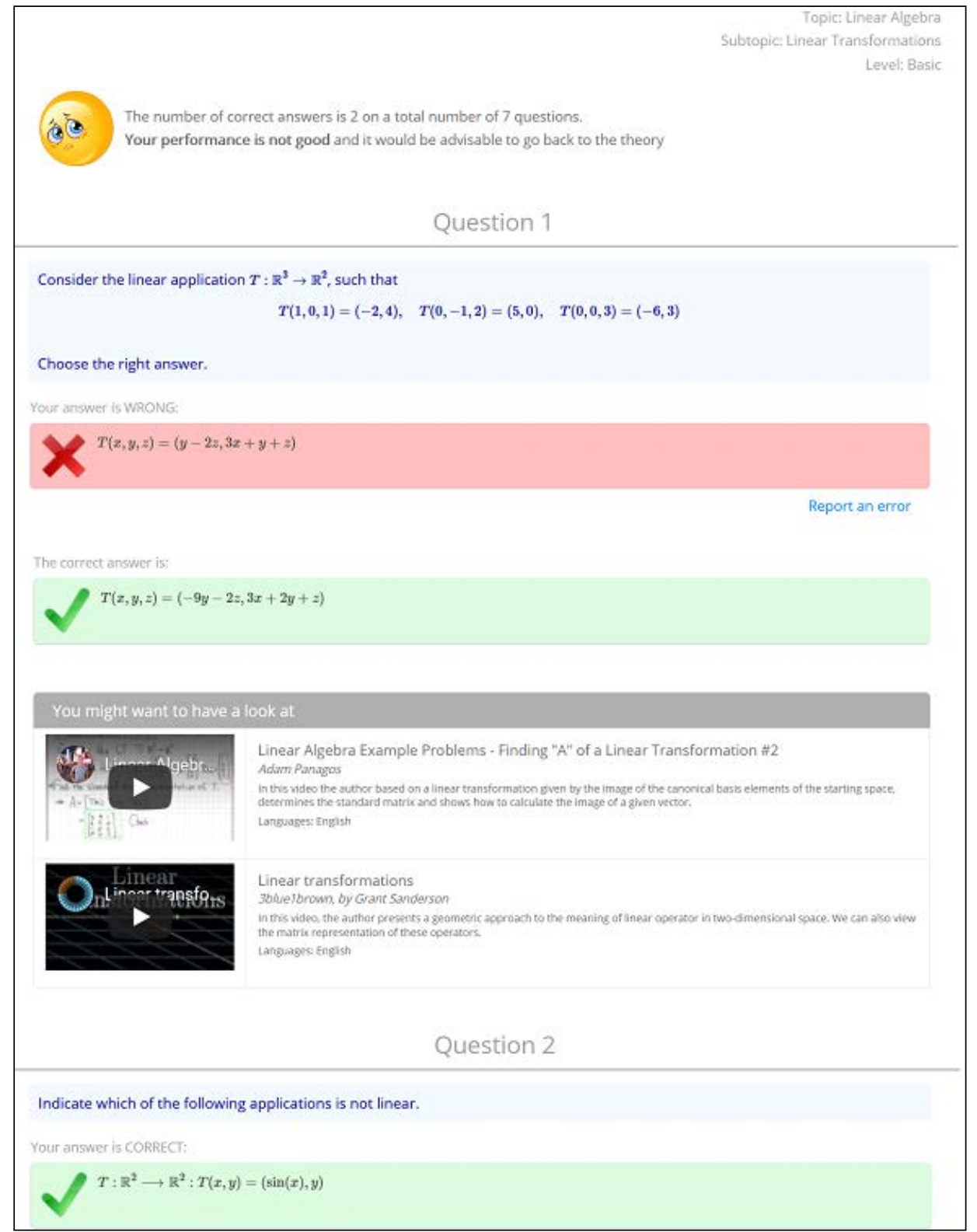

Figure 2. Feedback on the answers given in a test.

In addition to the information on the number of answers that got/missed, information is also provided on which is the correct answer, in the cases where it was wrong (see Fig. 2). In order to clarify the questions whose answer was wrong, the platform suggests viewing videos (Video Collection) and/or consulting specific documentation (Teaching Material) about the concepts involved and the procedures to be performed. All of this documentation, still under development, aims to elucidate processes for resolving issues whose correct answer has not been achieved.

\subsubsection{Linear algebra classes}

All Engineering or Technology courses at the institution where the study was carried out are part of a course unit where contents of linear algebra are treated. Particularly, the Bachelor in Biomedical Technology (TB), Chemical Engineering (EQ), Computer Engineering (El), Mechanical Engineering (EM) and Electrotechnical and Computer Engineering (EEC), integrate the so-called Linear Algebra 
and Geometry Analytical course unit, given in the 1st semester of the 1st year. Its programmatic contents, considered in the order in which they are usually taught, cover the topics Complex numbers, Matrices and determinants, Systems of linear equations, Analytical geometry in the plane and space, Vector spaces, Linear transformations and Values and eigenvectors.

In methodological terms, the teaching component follows the form of theoretical-practical sessions, where content is approached and justifications are presented almost always by way of example. A significant part of the sessions is oriented towards solving exercises by students and with the necessary contributions from the teacher. Tasks are also proposed to students, to be carried out individually or in groups, inside or outside the classroom, which contribute to the summative evaluation component. It was in this context, that the authors, being teachers at the same time, tried to propose the realization of training tests through the Self Need Assessment component of the MathE platform. The students were instructed to solve basic and advanced tests on the Vector Spaces (VS) and Linear Transformations (LT) subtopics.

As these tests are multiple choice, students were asked to submit their resolutions/justifications. We believe that justifications enable the development of written communication skills in mathematical language. On the other hand, they give us the necessary feedback on the understanding of the concepts involved. With the risk that the students did not address all the content being evaluated in the test generated, it was determined that they could choose to resolve only five of the seven test questions.

The methodology for carrying out the tasks was adapted by each teacher, based on the constraints of a temporal order and the specific needs of each group. Students in the El course performed only two tasks, a basic EV test and an advanced TL test. All students in the remaining courses performed two tasks on each topic, one at a basic level and one at an advanced level. Also, while the EQ and TB and El students took the tests right after the subjects were taught, the EM and EEC students solved these tests after the two themes had already been covered, with the intention that students perform the training and self-assessment, necessary to submit to the summative assessment of these subjects.

In all courses, basic level tests were carried out individually, within the scope of homework. Advanced level tests were carried out in groups and in the classroom and the teacher could ask for clarification if doubts arose.

\subsection{Participants in the study}

As participants in the study, 84 students from the referred courses were considered, who performed at least one of the tasks of each of the subtopics and answered a questionnaire where they express their opinion about the experience with the platform. More specifically, 11 students in a class that comprised the Bachelor in EQ and TB and 21, 26 and 26 in the Bachelor in EEC, EM and El, respectively.

The age level of the participants in the study varies between 18 and 41 years old, with mode and the median age being 20 years old. Most students completed their high studies in Portugal $(51.2 \%)$, with a significant percentage who studied in an African country (44\%), with the rest studying in Brazil $(4,8 \%)$.

\subsection{Methods of information collection and data analysis}

The evaluation of the experience was made based on the students' productions, on the researchers' observations and opinions, as teachers of the classes (condition of participating observer), and on a questionnaire applied to the students. This had, essentially, aimed to gather their opinion about the platform, more specifically on:

a) The questions themselves and their resolution: the scope and integration in the UC, the degree of complexity, the difficulties in solving and the interaction that students had with peers in this process.

b) The global enhancement of the platform, based on learning, motivation, autonomy, and language and interface.

c) Difficulties experienced in self-assessment through the platform.

d) Possibility to make assessment tests through the platform.

e) Suggestions to improve the platform.

In the case of the aspects mentioned in (a) and (b), the students gave their opinion on several items, based on a four-level Likert scale: 1 - Strongly disagree; 2 - Disagree; 3 - Agree and 4 - Totally agree. As for those mentioned in (c), (d) and (e) the questions were of open answer. In the data 
analysis, in the case of closed answers, were used descriptive statistics techniques, namely the calculation of frequencies organized in tables as a way to structure and synthesize the information. In the case of open answer questions, were defined categories, posteriorly, from the students' answers.

In this paper, the focus is essentially on the analysis of the platform's self-assessment component.

\section{RESULTS}

As mentioned, students solved, individually, at least one task with questions of basic level and another, in group, with questions of advanced level. In Fig. 3 is presented an example of a basic level question of the VS subtopic and in Fig. 4 the respective resolution made by one of the students.

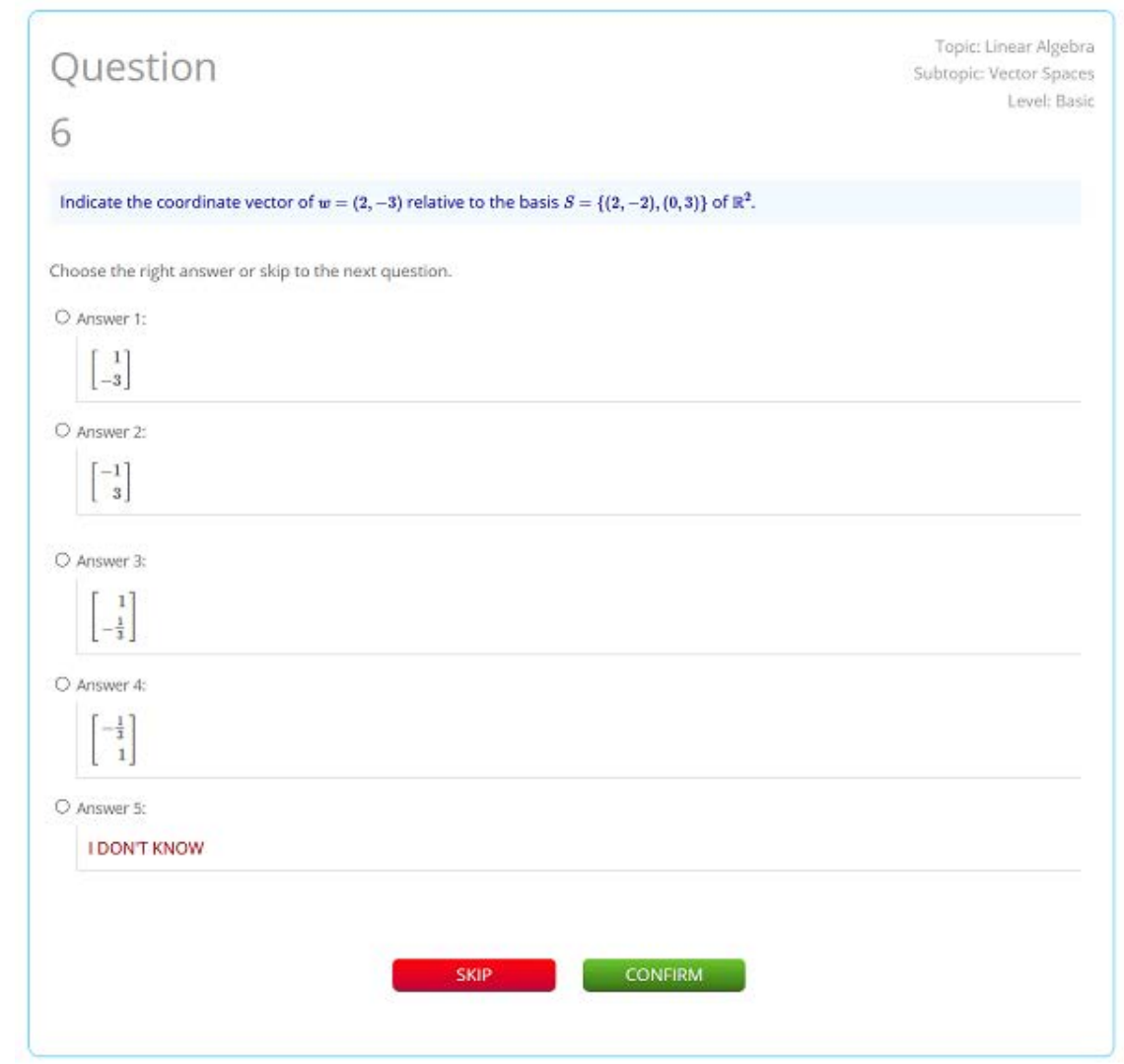

Figure 3. Question of the basic level of VS.

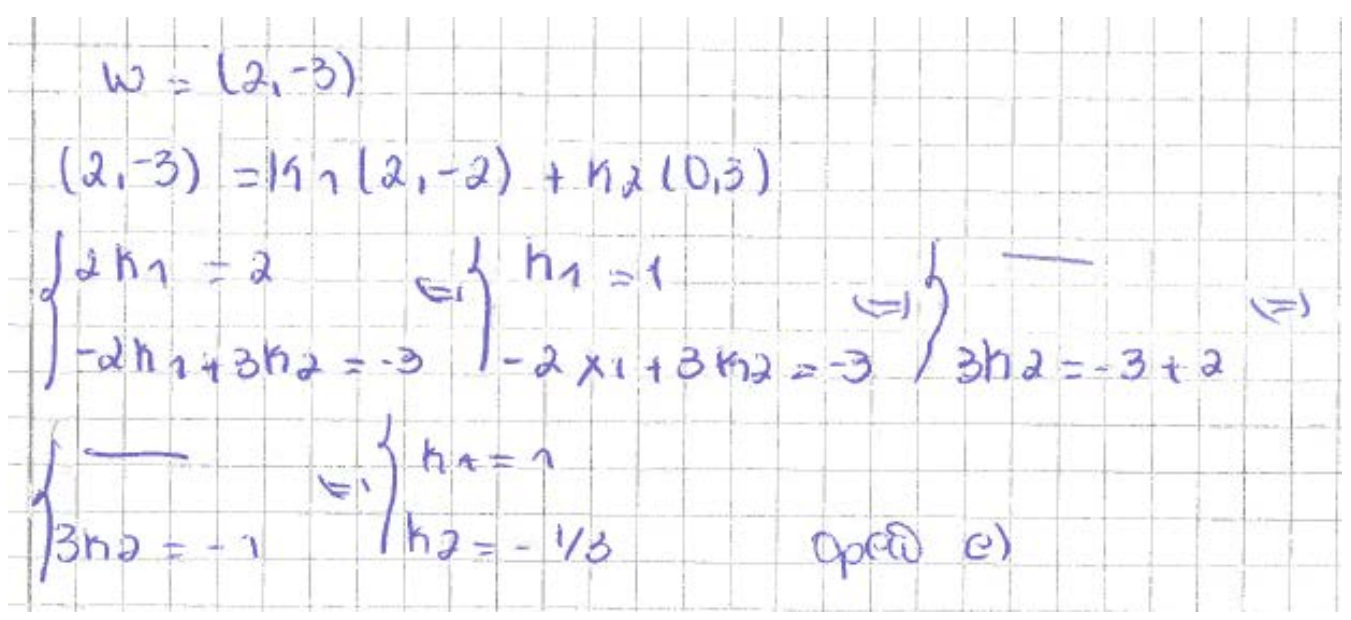

Figure 4. Resolution by a student of the question presented in Fig. 3. 
When solving this question, the student chose to solve the system resulting from the application of the definition of the linear combination, although he could also have chosen to substitute the coordinates given in each answer and check in which one would arrive at a true statement. However, it is considered that the student's reasoning is more embracing and reflects procedures already used in the classroom. Besides that, this more general strategy easily resolves issues that are not multiple choice.

The Fig. 5 shows an example of an advanced level question of the LT subtopic, in which given the transformation of the elements of a basis of the starting set, is requested the transformation of a vector of that space.

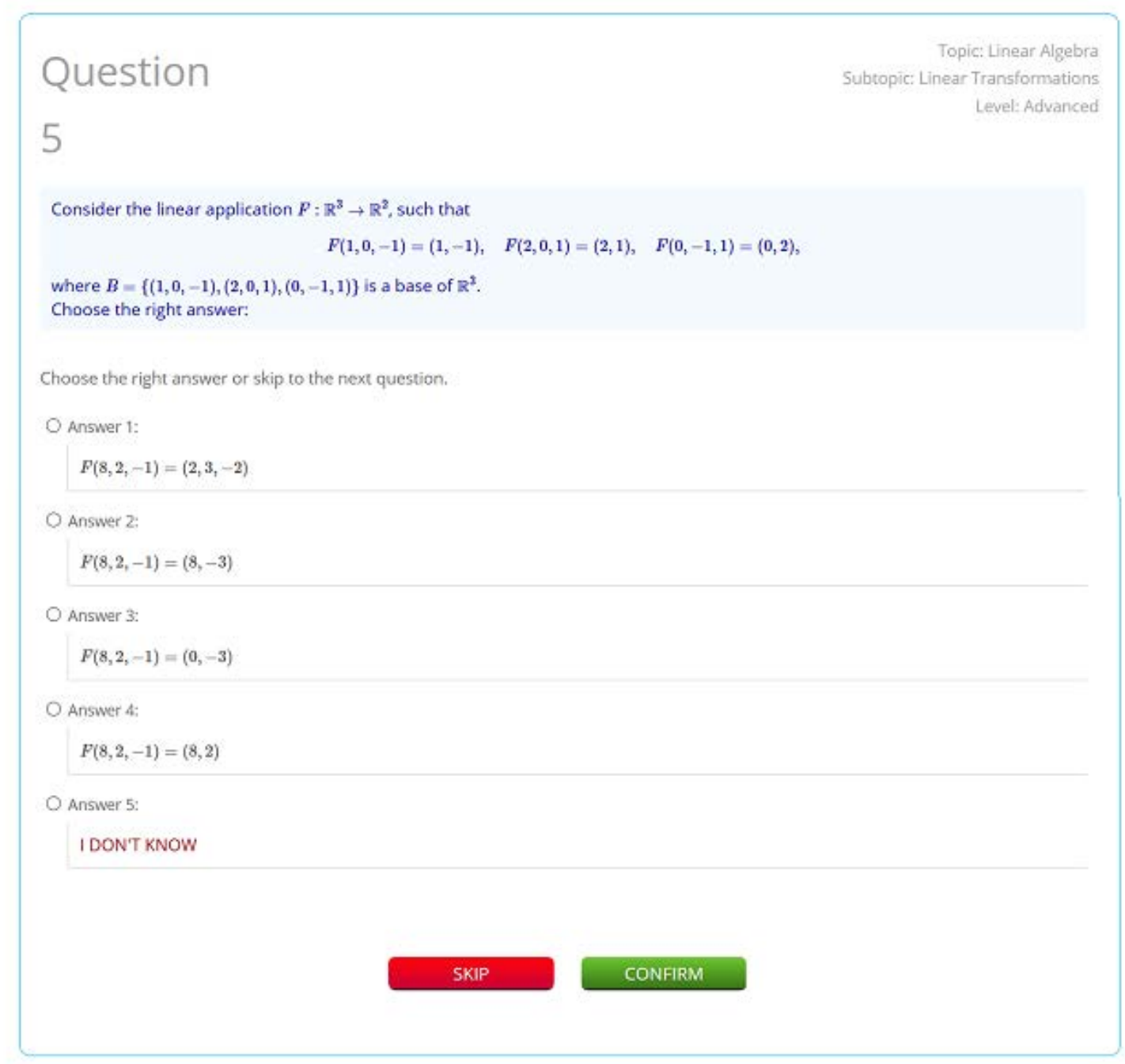

Figure 5. Question of LT of the advanced level.

As in the case of the VS question presented (Fig. 3 and Fig. 4), the students would initially have to find the coordinates of the vector $(8,2,-1)$ in the basis B of the starting set, but this time the method used to solving the resulting system was the Gaussian elimination method, which is part of the UC contents (Fig. 6). 


$$
\begin{aligned}
& (8,2,-1)=C_{1}(1,0,-1)+C_{2}(2,0,1)+c_{3}(0,-1,1) \\
& c_{1}\left[\begin{array}{c}
1 \\
0 \\
-1
\end{array}\right]+c_{2}\left[\begin{array}{l}
2 \\
0 \\
1
\end{array}\right]+c_{3}\left[\begin{array}{c}
0 \\
-1 \\
1
\end{array}\right]=\left[\begin{array}{c}
8 \\
2 \\
-1
\end{array}\right] ;\left\{\begin{array}{r}
c_{1}+2 c_{2}=8 \\
-c_{3}=2 \\
-c_{1}+c_{1}+c_{3}=-1
\end{array}\right.
\end{aligned}
$$

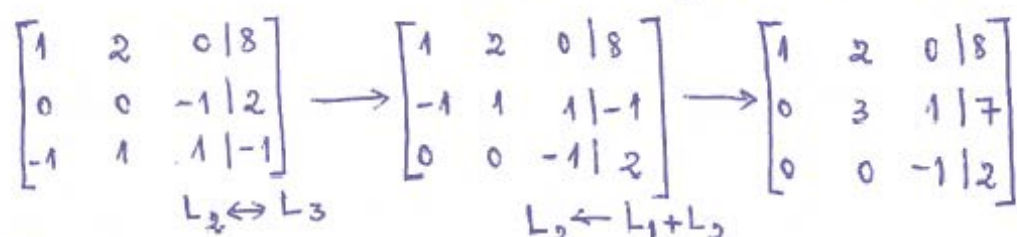

$$
\begin{aligned}
& \left\{\begin{array} { r l } 
{ c _ { 1 } + 2 c _ { 2 } } & { = 8 } \\
{ 3 c _ { 2 } + c _ { 3 } } & { = 7 } \\
{ - c _ { 3 } } & { = 2 }
\end{array} \Leftrightarrow \left\{\begin{array} { l } 
{ c _ { 1 } + 2 c _ { 2 } = 8 } \\
{ 3 c _ { 2 } + c _ { 3 } = 7 } \\
{ c _ { 3 } = - 2 }
\end{array} \Leftrightarrow \left\{\begin{array}{l}
c_{1}+2 c_{2}=8 \\
3 c_{2}+(-2)=7
\end{array} \Leftrightarrow\right.\right.\right. \\
& \Leftrightarrow\left\{\begin{array} { l } 
{ c _ { 1 } + 2 c _ { 2 } = 8 } \\
{ c _ { 2 } = 3 }
\end{array} \Leftrightarrow \left\{\begin{array}{l}
c_{1}+2 \cdot 3=8 \\
-\left\{\begin{array}{l}
c_{1}=2 \\
c_{2}=3 \\
c_{3}=-2
\end{array}\right.
\end{array}\right.\right. \\
& T(8,2,-1)=c_{1} T(1,0,-1)+c_{2} T(2,0,1)+c_{3} T(0,-1,1) \\
& (8,2,-1)=c_{1}(1,-1)+c_{2}(2,1)-c_{3}(0,2) \\
& \begin{array}{l}
=2(1,-1)+3(2,1)-2(0,2) \\
=(8,-3)
\end{array}
\end{aligned}
$$

Figure 6. Resolution of the question of the Fig. 5 presented by a group.

On the issues of the Self Need Assessment component, more than $85 \%$ of the students considered that both the basic and advanced levels of the VS and LT subtopics were in accordance with the contents covered in the classes (Tab. 1).

Table 1. Students' opinions on basic/advanced level issues of VS and LT.

\begin{tabular}{l|c|c|c|c|c|c|c|c}
\hline \multirow{2}{*}{$\begin{array}{l}\text { Opinion on Basic/Advanced } \\
\text { questions }\end{array}$} & \multicolumn{4}{c|}{ Vector Spaces (\%) } & \multicolumn{3}{c|}{ Linear Transformations (\%) } \\
\cline { 2 - 10 } & \multicolumn{2}{|c|}{ Basic } & \multicolumn{2}{c|}{ Advanced } & \multicolumn{2}{c}{ Basic } & \multicolumn{2}{c}{ Advanced } \\
\cline { 2 - 10 } & SD/D & A/TA & SD/D & A/TA & SD/D & A/TA & SD/D & A/TA \\
\hline $\begin{array}{l}\text { They were in agreement with the } \\
\text { concepts covered in class }\end{array}$ & 4.8 & 95.2 & 12.1 & 87.9 & 10.3 & 89.7 & 9.5 & 90.5 \\
\hline $\begin{array}{l}\text { The resolution of the questions } \\
\text { created many difficulties }\end{array}$ & 41.7 & 58.3 & 43.1 & 56.9 & 37.9 & 62.1 & 25.0 & 73.8 \\
\hline $\begin{array}{l}\text { The resolution of the questions } \\
\text { required many calculations }\end{array}$ & 42.9 & 57.1 & 37.9 & 62.1 & 41.4 & 56.9 & 35.7 & 63.1 \\
\hline $\begin{array}{l}\text { In most questions the answer was } \\
\text { obvious }\end{array}$ & 75.0 & 25.0 & 79.3 & 20.7 & 70.7 & 29.3 & 75.0 & 23.8 \\
\hline $\begin{array}{l}\text { I discussed the resolution with my } \\
\text { colleagues }\end{array}$ & 32.1 & 65.5 & 12.1 & 86.2 & 27.6 & 72.4 & 13.1 & 84.5 \\
\hline \hline
\end{tabular}

SD/D - Strongly Disagree or Disagree; A/TA - Totally Agree or Agree.

As for the degree of complexity of the questions, only a small percentage of students $(25 \%-29.3 \%$ at the basic level, $20.7 \%-23.8 \%$ at the advanced level) consider the answers obvious. In addition, more than half (between $55 \%$ and $64 \%$ ) consider that the resolution of the questions requires many calculations. This requirement is seen similarly in both subtopics, with a small increase in the case of advanced level questions. It is also noted that more than $55 \%$ of students agree or totally agree (A/TA) that the questions solving generated many difficulties. It should be noted that this percentage is higher 
in LT questions (62.1\% - Basic, $73.8 \%$ - Advanced) compared to those in VS (58.3\% - Basic, $56.9 \%$ Advanced), even in basic level (Tab. 1). This difference can be explained by the fact that many of the contents of LT require knowledge of VS.

Regarding the procedures, there is a tendency for students to discuss resolutions with their peers, even when it is not proposed that they be made in group, as is the case with basic level questions. It should be noted that $65.5 \%$ and $72.4 \%$ of the students claim to have discussed the resolution with their colleagues, in the case of VS and LT questions, respectively (Tab. 1).

The students' opinion about the platform is based on their experience with the Self Need Assessment component of the topic Linear Algebra, which was explored in the context of the classes. In general terms, students make a favourable assessment of its use. For example, with regard to aspects related to learning, more than $89 \%$ of students consider that the self-assessment process through the platform helps to identify errors, is an asset for learning and constitutes an important tool to support learning study. Likewise, more than three quarters of students consider that this tool contributes to increase motivation and develop their autonomy (Tab. 2).

Table 2. Students' opinions about the MathE platform.

\begin{tabular}{l|c|c}
\hline \multicolumn{1}{c|}{ I think the MathE platform } & $\begin{array}{c}\text { Strongly Disagree } \\
\text { or Disagree (\%) }\end{array}$ & $\begin{array}{c}\text { Agree or Totally } \\
\text { Agree (\%) }\end{array}$ \\
\hline Help me to identify the mistakes made, as it validates my answers & 10.7 & 89.3 \\
\hline It is an asset for my learning in algebra & 9.5 & 89.3 \\
\hline It is an important tool to support individual study & 7.1 & 92.9 \\
\hline Increases my motivation to learn ALGA & 21.4 & 78.6 \\
\hline It is a motivating tool in the classroom & 13.1 & 85.7 \\
\hline $\begin{array}{l}\text { It increases my autonomy, as I don't depend on the teacher to } \\
\text { correct my answers }\end{array}$ & 11.9 & 86.9 \\
\hline $\begin{array}{l}\text { It challenges me to persist in trying to solve the questions where I } \\
\text { made mistakes, because I know what are the right options }\end{array}$ & 10.7 & 88.1 \\
\hline Because it is in English, it makes it difficult to understand the questions & 40.5 & 57.1 \\
\hline It is not viable for me due to my difficulties with the English language & 59.5 & 39.3 \\
\hline Features an accessible user interface & 17.9 & 82.1 \\
\hline \hline
\end{tabular}

Concerning the interface, it appears that more than three quarters of the students consider that it is accessible to the user. The fact that the predominant language on the platform is the English, can make it difficult to understand the questions, at least in the opinion of $57.1 \%$ of students. Although the majority $(59.5 \%)$ do not consider that the language barrier makes it unfeasible to use, there is a significant percentage $(40.5 \%)$ for which this aspect constitutes a relevant obstacle (Tab. 2). It is noteworthy that when asked about the difficulties experienced in the self-assessment process, the aspect most focused by the students was the language used: "Interpretation of the questions, because the platform is in the English language", "The biggest difficulty is because it is in another language, and there are some technical words in that same language".

As previously mentioned, the advanced level tests were carried out in the classroom, which allowed teachers to assist in the translation of questions and clarification of what was intended, as well as to clarify other doubts that arose. It was also provided support in basic level tasks performed outside the classroom, whenever students requested it. This support, receiving feedback from the platform, being able to consult information on the internet, exchanging ideas with peers, having to hand in their resolutions / explanations, coupled with the fact that the work carried out contributed to the final assessment, led the students to be motivated and committed to identify your mistakes and try to perform well in solving tasks. In this way, the combination of the Self Need Assessment component allied with other strategies allowed to take better advantage of the platform's potential. 


\section{CONCLUSIONS}

The opinion of the students about the MathE platform is very positive, both with regard to accessibility, as well as for their contribution from the motivational point of view, of learning and the development of their autonomy. It should also be noted that the fact that the "Self Need Assessment" component provides feedback on the answers given can encourage students to identify their mistakes and seek information (recommendations for teaching materials and videos are already available and will soon cover all questions) to clarify your doubts and thus overcome your difficulties. Note that strategies that allow students to identify and correct their own mistakes can be an important aid in combating the failure of linear algebra in higher education (e.g. [5]).

The main impediment, pointed out by the students to the use of the platform, is the language barrier, which is understood by the fact that many of them, although they are from countries of Portuguese official language, also speak, in an informal context, their dialects. This way, they will have, in academic terms, to adapt to three different languages: the portuguese, the english and the mathematics. In addition, even when students have skills in the English language, the linear algebra language has its own terminology, which is not commonly used in everyday life. The resolution of the situation may involve the creation of a resource that allows a specialized translation into Portuguese, following the terminology used in the area of mathematics, or, alternatively, having a glossary of the most used specific terms, which can be translated into several languages.

In conclusion, the MathE platform can be an important tool to promote learning in the field of "advanced mathematics", especially when complemented with other approaches, having special relevance in contexts where online learning or b-learning is fundamental.

\section{ACKNOWLEDGEMENTS}

This work is supported by MathE - Improve Math Skills in Higher Education financed by Erasmus+ Programme's Strategic Partnerships No. 2018-1-PT01-KA203-047361.

\section{REFERENCES}

[1] K. Juklová, "Three influential concepts on the background of academic learning," Bulletin of the Transilvania University of Brasov, Series VII: Social Sciences and Law, vol. 9 (2-Suppl), pp. 165178, 2016. Retrieved from http://webbut.unitbv.ro/bulletin/

[2] M.L. Lima, I. Menezes and L. Carregã, "O ensino superior como um espaço de formação multifacetado," in Manual de competências académicas: Da adaptação à universidade à excelência académica (M.V. Garrido and M. Prada, coords.), pp. 69-84, Lisboa/Portugal: Sílabo, 2016.

[3] M. Cepillo-Galvín, "Aprendizaje basado en problemas (APB)," in Técnicas docentes y sistemas de evaluación en Educación Superior (M.P. Sánchez-González, org.), pp. 31-36, Madrid/Spain: Narcea, 2010.

[4] M. D. Cervilla-Garzón, "Elaboración de supuestos prácticos," in Técnicas docentes y sistemas de evaluación en Educación Superior (M.P. Sánchez-González, org.), pp. 53-60, Madrid/Spain: Narcea, 2010.

[5] P.M. Barros, O ensino e a aprendizagem de conceitos de álgebra linear no ensino superior politécnico (Tese de doutoramento). Braga/Portugal: Universidade do Minho, 2018.

[6] P.M. Barros, J.A. Fernandes and C.M. Araújo, "Prontidão de alunos do ensino superior para a aprendizagem da álgebra linear," Educação Matemática Pesquisa, vol.18, no. 1, pp. 43-59, 2016.

[7] P.M. Barros, F. Silva and J.A. Fernandes, "Transição secundário-superior: diagnóstico dos conhecimentos matemáticos de alunos portugueses e africanos," in LUSOCONF2019 - II Encontro Internacional de Língua Portuguesa e Relações Lusófonas: livro de atas, Bragança/Portugal: Instituto Politécnico de Bragança, in press.

[8] V.L. Uzuriaga, J.J. Arias and A. Martinez, "Diagnóstico y análisis de algunas causas que dificultan el aprendizaje del algebra lineal en estudiantes de ingeniería," Scientia et Technica, vol. 2, no. 39, pp. 404-409, 2008. 
[9] V.L. Uzuriaga, J.J. Arias and D.G. Manco, "Algunas causas que determinan el bajo rendimento académico en el curso de álgebra lineal," Scientia et Technica, vol. 1, no. 44, pp. 286-291, 2010.

[10] D.I. Andreoli, "Construcción de los conceptos de dependencia e independencia lineal de vectores en alumnos de primer año de la universidad (Tercera fase)," in Comunicações Científicas y Tecnológicas 2005, Argentina: Universidade Nacional del Nordeste, 2005. Retrieved from http://host140.200-45-54.telecom.net.ar/unnevieja/Web/cyt/com2005/9-Educacion/D-004.pdf

[11] N. Aygor and H. Burhanzade, "The comparative analyzes of the student's performance about matrix in Student Selection Exam (ÖSS) and the Approved Lecture Books of Ministry for the National Education (MEB)," Procedia Social and Behavioral Sciences, no. 136, pp. 360-369, 2014.

[12] D.K. Birinci, A. Delice and E. Aydin, "University students' solution processes in systems of linear equation," Procedia Social and Behavioral Sciences, no. 152, pp. 563-568, 2014.

[13] S. Britton and J. Henderson, 'Linear algebra revisited: an attempt to understand students' conceptual difficulties," International Journal of Mathematical Education in Science and Technology, vol. 40, no. 7, pp. 963-974, 2009.

[14] V.C. Cardoso, L.A. Kato and S.R. Oliveira, "Um estudo no campo conceitual de Vergnaud aplicado às matrizes: uma investigação acerca dos invariantes operatórios," Revemat: Revista Eletrônica de Educação Matemática, no. 8, pp. 95-116, 2013.

[15] R.A. Cerutti and D.I. Andreoli, "Construcción de los conceptos de dependencia e independencia lineal de vectores en alumnos de primer año de la universidad (Primera fase) in Comunicações Científicas y Tecnológicas 2002, Argentina: Universidade Nacional del Nordeste, 2002. Retrieved from http://www.unne.edu.ar/unnevieja/Web/cyt/cyt/2002/09-Educacion/D-018.pdf

[16] J-L. Dorier and A. Sierpinska, "Research into the teaching and learning of linear algebra," in The teaching and learning of mathematics at university level (D. Holton, ed.), 255-273, Dordrecht: Springer, 2001.

[17] J. Hillel, "Modes of description and the problem of representation in linear algebra," in On the teaching of linear algebra (J-L. Dorier, ed.), 191-207, Dordrecht: Springer, 2000.

[18] M. Karrer, Articulação entre Álgebra Linear e Geometria: um estudo sobre as transformações lineares na perspectiva dos registros de representação semiótica (Tese de doutoramento). São Paulo/Brasil: Pontifícia Universidade Católica de São Paulo, 2006.

[19] M. Zandieh and Andrews-Larson, "Solving linear systems: augmented matrices and reconstruction of $\mathrm{x}$," in Proceedings of the 18th Annual Conference on Research in Undergraduate Mathematics Education (T. Fukawa-Connelly, N. E. Infante, K. Keene and M. Zandieh, eds.), pp. 1072-1078, Pittsburgh/Pennsylvania: The Special Interest Group of the Mathematics Association of America (SIGMAA) for Research in Undergraduate Mathematics Education, 2015. 